Running head: In-Exsufflation Pressure Titration

\title{
Peak Cough Flow Fails to Detect Upper Airway Collapse during Negative Pressure
}

\section{Titration for Cough-Assist}

Matthieu Lacombe PT MSc ${ }^{\text {a }}$, Aurélien Boré PT a, Lorena Del Amo Castrillo PT a,

Ghilas Boussaïd $\mathrm{PhD}^{\mathrm{b}}$, Line Falaize $\mathrm{AS}^{\mathrm{a}, \mathrm{b}}$, Erica Vlachos $\mathrm{MSc}^{\mathrm{a}}$,

David Orlikowski MD PhD ${ }^{\mathrm{a}, \mathrm{b}}$, Hélène Prigent $\mathrm{MD} \mathrm{PhD}{ }^{\mathrm{a}, \mathrm{b}}$, Frédéric Lofaso MD PhD ${ }^{\mathrm{a}, \mathrm{b}}$

${ }^{a}$ Réanimation Médicale, Physiologie - Explorations Fonctionnelles, et Centre d'Investigation

Clinique UMR 1429, Hôpital Raymond Poincaré, AP-HP, 104 Boulevard Raymond Poincaré, 92380 Garches, France

${ }^{\mathrm{b}}$ INSERM-UMR 1179, Université de Versailles Saint-Quentin-en-Yvelines, Hôpital Raymond Poincaré, AP-HP, 104 Boulevard Raymond Poincaré, 92380 Garches, France

\section{Corresponding author: Prof. Frédéric LOFASO}

Services de Physiologie et Explorations Fonctionnelles

Hôpital Raymond Poincaré, AP-HP,

92380 Garches, France

Tel.: +33147107941

Fax: +33147107943

E-mail: f.lofaso@ aphp.fr

Funding: This research did not receive any specific grant from funding agencies in the public, commercial, or not-for-profit sectors.

Disclosures: none

Clinical Trial Registration: ClinicalTrials.gov [\#NCT02137304] 
1 ABSTRACT

2 Objective: To study the ability of peak cough flow (PCF) and effective cough volume (ECV),

3 defined as the volume exsufflated above $3 \mathrm{~L} / \mathrm{s}$, to detect upper airway collapse (UAC) during

4 mechanical insufflation-exsufflation (MI-E) titration in neuromuscular patients.

5 Design: Prospective observational study

6 Setting: Rehabilitation hospital

7 Participants: Twenty-seven patients with neuromuscular disease causing significant impairment

8 of chest wall and/or diaphragmatic movement.

9 Interventions: The lowest insufflation pressure producing the highest inspiratory capacity was

10 used. Exsufflation pressure was decreased from $-20 \mathrm{cmH}_{2} \mathrm{O}$ to $-60 /-70 \mathrm{cmH}_{2} \mathrm{O}$, in $10-\mathrm{cmH}_{2} \mathrm{O}$

11 decrements, until UAC was detected using the reference standard of flow-volume curve analysis

12 (after PCF, abrupt flattening or flow-rate decrease versus previous less negative exsufflation

13 pressure).

14 Main outcomes: Peak cough flow and ECV profiles during expiration with MI-E.

15 Results: Upper airway collapse occurred in 10 patients during titration. ECV increased with

16 decreasing expiratory pressure then decreased upon UAC occurrence. PCF continued to increase

17 after UAC occurrence. In 5 other patients, UAC occurred at the initial $-20 \mathrm{cmH}_{2} \mathrm{O}$ exsufflation

18 pressure and, during titration, PCF increased and ECV remained unchanged at less than $200 \mathrm{~mL}$.

19 PCF had $0 \%$ sensitivity for UAC, whereas ECV had 100\% sensitivity and specificity.

20 Conclusion: Of 27 patients, 15 experienced UAC during MI-E titration. UAC was associated

21 with an ECV decrease or plateau and with increasing PCF. Accordingly ECV, but not PCF, can

22 detect UAC. 
24 Keywords: cough, mechanical insufflation-exsufflation, neuromuscular disease, exsufflation,

25 upper airway collapse

26

27

28 List of abbreviations:

29 ECV : effective cough volume

30 MEP: maximum expiratory pressure

31 MI-E: mechanical insufflation-exsufflation

32 MIP: maximum inspiratory pressure

33 NMD: neuromuscular disease

34 OSA: obstructive sleep apnea

35 PCF: peak cough flow

36 UAC: upper airway collapse

37 VC: vital capacity

38

39

40

41

42

43 


\section{INTRODUCTION}

Poor cough efficiency resulting in an inability to clear the airways of secretions is a major risk factor for acute respiratory failure in patients with neuromuscular disease (NMD). ${ }^{1,2}$ Coughassistance methods include manual and mechanical techniques providing inspiratory and/or expiratory assistance to improve cough efficiency, mobilize and clear the airway secretions, and avoid complications associated with secretion retention. ${ }^{1-6}$ Peak cough flow (PCF) is usually taken as the criterion for determining that airway clearance is effective, the cut-off being 160-180 $\mathrm{L} / \mathrm{min}$ in adults with NMD. ${ }^{7-13} \mathrm{~A}$ baseline $\mathrm{PCF}<180 \mathrm{~L} / \mathrm{min}(3 \mathrm{~L} / \mathrm{s})$ is required for reimbursement of secretion-clearance devices by the statutory health insurance systems in Belgium ${ }^{14}$ and France. ${ }^{11}$ Rather than to use a PCF threshold U.S. health insurance companies prefer a clinical $\underline{\text { evaluation and criteria for MI-E devices (E0482) covering are : 1) a neuromuscular disease (refer }}$ $\underline{\text { to the 10th revision of the "International Statistical Classification of Diseases and Related Health }}$

5 Problems“), and 2) this condition is causing a significant impairment of chest wall and/or

diaphragmatic movement, resulting in an inability to clear retained secretions.

Peak cough flow is also the most widely used parameter for assessing the performance of cough-assist techniques in patients with NMD. ${ }^{8,15,16}$ Mechanical insufflation-exsufflation (MI-E)

is currently considered the technique of choice for the weakest patients with NMD. ${ }^{6}$ The

2 insufflation pressure that achieves the highest PCF is viewed as optimal and is lower than the value providing maximal insufflation. ${ }^{17}$ It has been suggested that the optimal exsufflation pressure can also be defined as the value achieving the highest PCF. However, PCF measurement may fail to detect upper airway collapse (UAC) caused by the application of negative pressure.

UAC may impair cough effectiveness according to two studies showing evidence of upper airway 
obstruction during MI-E. ${ }^{18,19}$ However, the techniques used in these studies ${ }^{18,19}$ are not readily applicable to exsufflation pressure titration in everyday practice.

We hypothesized that, when upper airway collapse occurs during titration, the exsufflation pressure achieving the highest volume exhaled at an efficient flow [i.e. above 3 $\mathrm{L} / \mathrm{min}$ ], designated as "effective cough volume" (ECV), is systematically higher (i.e. less negative) than the exsufflation pressure achieving the highest PCF value. The objective of this prospective study in patients with severe respiratory muscle weakness due to NMD was to investigate changes in PCF and ECV during MI-E, particularly upon the occurrence of UAC, as detected by analysis of the flow-volume curve. The performance of PCF and ECV in detecting UAC was quantified.

\section{MATERIAL AND METHODS}

\section{Patients}

This observational study was approved by the French national ethics committee and registered on ClinicalTrials.gov (\#NCT02137304). In 2016 and 2017, we enrolled 27 patients with NMD during their annual follow-up visits to the post-intensive care unit, which routinely included patient education about cough-assist techniques. All 27 patients met the French, Belgium and US criteria required for MI-E coverage. At each visit, the following parameters were recorded: vital capacity (VC),${ }^{20}$ unassisted $\mathrm{PCF},{ }^{20}$ maximum expiratory pressure (MEP), and maximum inspiratory pressure (MIP). ${ }^{21,22}$ Inclusion criteria were documented NMD, reason for using MI-E, age >18 years, hemodynamic stability, absence of acute bronchial congestion (respiratory tract infection) in the past month, and PCF lower than $4.5 \mathrm{~L} / \mathrm{s} .{ }^{5}$ Patients gave written informed consent before study inclusion. 


\section{Study protocol}

Mechanical insufflation-exsufflation was performed using a facemask [Ambu UltraSeal, Ambu, Bordeaux, France] and the Cough-Assist E70 device [JH Emerson Co., Cambridge, MA, USA]. Measurements during maneuvers were obtained with a spirometer (Micro 6000 spirometers; Medisoft, Sorinnes, Belgium) connected to the MI-E circuit and were performed with the study participants seated comfortably in their adapted wheelchair; the experiment was started after a period of quiet breathing. Patients were seated in their own electric wheelchair. Postural adjustments were made following patients' advice for their best respiratory comfort. Degree of tilt, recline or elevation of leg rests were not measured. If possible, the degrees of tilt and recline tried to allow the patient having an overall view on Cough-Assist E70 screen in order to get a visual feedback. The head was on the headrests maintained in the neutral position, when it was possible for the patient, to avoid bias due to effects of position on deep breathing and coughing. Throughout the tests, oxygen saturation and heart rate were monitored using pulse oximetry.

The day before testing, the patients were familiarised with the study cough-assist techniques. The optimal insufflation pressure was determined by starting at $10 \mathrm{cmH}_{2} \mathrm{O}$, increasing in $5 \mathrm{cmH}_{2} \mathrm{O}$ steps up to $20 \mathrm{cmH}_{2} \mathrm{O}$, and finally increasing further in $2 \mathrm{cmH}_{2} \mathrm{O}$ steps to a maximum of $40 \mathrm{cmH}_{2} \mathrm{O}$. Measurements were performed two or three times at each pressure level. The individual pressure titration was stopped when further increase did not lead to additional improvement or if patients did not tolerate higher pressures. ${ }^{17}$ Insufflation poor tolerance was defined as an overinflation sensation hindering the compression phase of cough. 
115 MI-E device and the other performed the measurements. Great care was taken to avoid leaks

116 around the mask during MI-E. The physiotherapists stimulated the patient's efforts to cough via

117 strong verbal encouragement. MI-E was delivered via a facemask (Ambu UltraSeal ${ }^{\mathrm{b}}$ ) using the

118 Cough-Assist E70 ${ }^{c}$ device in automatic mode, as operator-bias might have occurred in manual

119 mode. The duration of insufflation-exsufflation was set at $2.5 \mathrm{~s}$. The optimal insufflation pressure

120 determined on the previous day was used. Exsufflation pressure titration was performed starting

121 at $-20 \mathrm{cmH}_{2} \mathrm{O}$ then decreasing in $10 \mathrm{cmH}_{2} \mathrm{O}$ steps to $-60 \mathrm{cmH}_{2} \mathrm{O}$. For those patients expressing

122 the wish to test the limits of the device, the exsufflation pressure was further decreased up to -70

$123 \mathrm{cmH}_{2} \mathrm{O}$. Each exsufflation pressure was tested at least three times, ${ }^{23}$ and the best flow-volume

124 curve was retained for the analysis, which included determination of the highest volume

125 exsufflated at a flow greater than $3 \mathrm{~L} / \mathrm{s}$ (see below).

126 Individual exsufflation pressure titration was stopped when a further decrease was poorly

127 tolerated by the patient or when an alteration in the flow-volume curve suggested UAC.

128 Exsufflation poor tolerance was defined as an upper airway irritation and/or an UAC sensation

129 limiting expiration and/or a dyspnea increase and/or a desynchronization between the patient and

130 the cough device assistance. Flow-volume curve was considered altered by the physiotherapists

131 on the basis of studies previously described with the negative expiratory pressure technique used

132 to assess upper airway collapsibility during spontaneous breathing to identify patients at risk for

133 obstructive sleep apnea (OSA) ${ }^{24}$. The spirometer used for the study automatically superimposed

134 successive flow-volume curves (Figure 1). A flow rate decrease occurring abruptly after PCF

135 measurement on at least part of the exhaled volume, compared to the flow rate observed at the

136 previous titration step, was thus taken to indicate UAC. In addition, abrupt flow-volume curve

137 flattening at the beginning of MI-E titration (i.e., at the highest negative exsufflation pressure of -

$13820 \mathrm{cmH}_{2} \mathrm{O}$ ) is very typical to UAC but does not allow for comparison to a previous flow-volume 
139 curve. Consequently, in this situation, UAC was diagnosed if further decreasing the negative

140 exsufflation pressure failed to improve the appearance of the flow-volume curve.

141 The UAC determination by flow-volume curve analysis was checked later by two 142 respiratory physiologists (FL and HP).

143 Patients could rest between each tested pressure level, and total patient participation did 144 not exceed 40 minutes.

\section{Statistical analysis} mean \pm SD for normally distributed continuous variables, and median [interquartile range] for skewed continuous variables. Inter-observer reliability of UAC detection based on the flow-

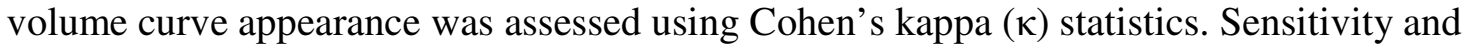

151 specificity of PCF and ECV for identifying UAC at the same negative exsufflation pressure

152 during MI-E titration were calculated. A segmented linear mixed-effects regression model was 153 built to assess changes in pressure over flow. Patients were categorized based on their flow-volume curve patterns. Comparisons across patient categories of relied on ANOVA for normally distributed and homoscedastic quantitative variables and on the Kruskal-Wallis test for non-normally distributed or probably nonhomoscedastic quantitative variables. Qualitative variables were compared across patient categories by applying the Mantel-Haenszel chi-square test or, when sample size was $<5$, Fisher's

159 exact test. All tests were two-tailed and $P$ values $<0.05$ were taken to indicate significant differences.

161 The statistical analyses were carried out with R software version 2.2.0. ${ }^{25}$ 
163

164

165

166

167

168

169

170

171 (Cohen's א=1).

172

173

174

175

176

177

178

179

180

181 flow, an abnormal abrupt fall in expiratory flow, which was confirmed when comparing these

182 flow-volume loop with those obtained with the previous and less negative exsufflation pressure

183 [profile B in Figure 2]. The exsufflation pressure at which UAC occured was $-70 \mathrm{cmH}_{2} \mathrm{O}$ in 1

184 patient, $-60 \mathrm{cmH}_{2} \mathrm{O}$ in 7 patients, and $-50 \mathrm{cmH}_{2} \mathrm{O}$ in 2 patients (Table 2). In one patient, a 
185 decrease in the tolerance characterized by an uninterrupted irritating cough occurred at -50

$186 \mathrm{cmH} 2 \mathrm{O}$ and was concomitant with occurrence of UAC (patient \#8 in Table 2). - profile $\mathrm{C}$ group [Figure 2, patient \#17; Table 2]: For the 5 remaining patients, UAC occurred at the beginning of titration. Accordingly the flow-volume curve flattened abruptly starting at the step that immediately followed the initial $-20 \mathrm{cmH}_{2} \mathrm{O}$ exsufflation pressure value and did not improve when decreasing expiratory pressure. In 3 patients, titration was stopped before reaching $-60 \mathrm{cmH}_{2} \mathrm{O}$, at $-50 \mathrm{cmH}_{2} \mathrm{O}$ in 1 patient and $-40 \mathrm{cmH}_{2} \mathrm{O}$ in 2 patients, because of a decrease in the tolerance characterized by clinical sensation of upper airway collapse.

\section{Peak cough flow (PCF)} UAC did or did not occur. Thus, PCF was always highest at the lowest exsufflation pressure tested. As shown in Figure 3, PCF increased steadily by about $0.32 \mathrm{~L} / \mathrm{s}$ per $10 \mathrm{cmH}_{2} \mathrm{O}$ from the beginning to the end of titration.

\section{Effective cough volume (ECV)}

In the group with profile A, ECV increased steadily from the beginning to the end of the exsufflation pressure decreased.

\section{Comparison between PCF and ECV}

The relative changes in PCF and ECV during negative exsufflation pressure titration are

208 reported in Figure 4. In profile A, PCF and ECV increased concomitantly. In profile B, ECV 
209 increased initially with PCF, until UAC occurred, after which ECV decreased while PCF

210 continued to increase. In profile C, PCF increased steadily, while ECV remained below $200 \mathrm{~mL}$.

211 Thus, UAC was always accompanied with an increase in PCF contrasting with either a decrease

212 in EVC or, when UAC occurred at the beginning of titration, a stable ECV value below $200 \mathrm{~mL}$.

213 A decrease in ECV versus earlier value had 100\% sensitivity and $100 \%$ specificity for detecting

214 UAC, whereas a decrease in PCF versus earlier value had $0 \%$ sensitivity and $100 \%$ specificity.

216 Comparison between patient groups with versus without upper airway collapse (UAC)

217 When we compared patients with versus without UAC diagnosed based on the flow-

218 volume curve (i.e., those with profile A versus those with profile B or C), we found no significant

219 differences in mechanical ventilation duration, VC, MIP, MEP, or baseline PCF $(P=0.78,0.32$,

$2200.58,0.12$, and 0.24 , respectively). The distribution of NMD diagnoses differed significantly

221 across the three flow-volume curve profiles (Fisher's exact test, $P=0.03$ ), chiefly because UAC

222 occurred during titration in all 4 patients with spinal muscular atrophy.

\section{DISCUSSION}

We report the first systematic evaluation of flow-volume curve profiles during exsufflation pressure titration for MI-E in patients with NMD. PCF, the parameter generally used to assess cough efficiency, increased consistently as exsufflation pressure decreased. However,

228 despite increasing PCF values, 15 of the 27 patients exhibited flow-volume curve findings

229 indicating UAC and coinciding with a decrease in ECV (defined as the volume coughed at a flow $230>3 \mathrm{~L} / \mathrm{s}$ ), suggesting impaired cough efficiency. In contrast when the flow-volume curve showed 231 no evidence of UAC, ECV increased steadily as the exsufflation pressure decreased. 
The maximum flow achievable during forced expiration or coughing started after maximal

233 or submaximal lung inflation is widely believed to be chiefly effort-dependent. ${ }^{26}$ However, after

234 the early peak flow, if sufficient expiratory effort is produced to cause dynamic compression of

235 the intrathoracic airways, flow becomes effort-independent (i.e., limited): beyond a given driving

236 pressure, additional force generated by the expiratory muscles does not further increase flow,

237 which diminishes progressively from the early peak until the end of the maneuver. ${ }^{26}$ This flow

238 limitation is explained by the drop in alveolar pressure along the airways that occurs during

239 expiration, due to airway resistance. The airway pressure may become equal to the intrapleural

240 pressure during forced expiration, i.e., may reach the equal pressure point. When the equal

241 pressure point is reached at the level of the trachea or large bronchi, the presence of hyaline

242 cartilage prevents airway collapse. ${ }^{26}$ However, due to the decrease in lung volume during forced

243 expiration, the alveolar elastic recoil pressure decreases and the equal pressure point moves

244 upstream towards the alveoli. The equal pressure point may then be reached at the thin-walled

245 bronchioles, which may collapse, inducing a typical depression in the flow-volume curve. ${ }^{26}$ This

246 phenomenon of intrathoracic airway compression and collapse is critical for the secretion

247 clearance mechanism, as it induces increases in linear velocity and kinetic airstream energy,

248 thereby improving the mobilization and expulsion of material from the bronchial tree. ${ }^{26}$

249 Accordingly, sufficient expiratory muscle force is required to reach the flow-limitation threshold.

250 Thus, the greater is the expiratory effort, the earlier is the flow limitation reached during the

251 forced expiratory maneuver and, therefore, the better is the flow-volume curve.

In many patients with NMD, the expiratory muscle weakness limits the production of a

253 satisfactory flow-volume curve. Expiratory muscle weakness does not allow an optimal driving

254 pressure in order to generate a high peak flow and reach the flow-limitation threshold. During the 255 expulsive phase of cough, this weak driving pressure becomes the main cause of expiratory flow 
256 reduction. Accordingly, applying negative pressure during expiration assist expiratory muscle

257 weakness and may increase the peak flow or PCF by increasing the driving pressure and may also 258 improve the second part of the expiratory flow-volume curve by reaching the flow-limitation 259 threshold. This effect of negative exsufflation pressure was seen in our patients with profile A.

260 However, as previously demonstrated in a few patients, if negative pressure induces UAC, ${ }^{18,19}$

261 adding further flow limitation, then the flow coming from the lungs may be altered from the 262 beginning to the end of the forced expiration. Moreover, airway collapse may be missed if only 263 peak flow or PCF is measured, as these parameters may be paradoxically increased at the mouth 264 when the collapse causes rapid expulsion of the air contained in the upper airway, although the 265 contribution to airway clearance of airflow from the intrathoracic airways may be reduced by the 266 upper airway obstruction. Our results support this possibility: in profile B seen in 10 of the 27 267 patients, PCF continued to increase with decreasing negative exsufflation pressure, but the ECV 268 decreased after a threshold, resulting in a flattening of the subsequent part of the flow-volume 269 curve. These results are also concordant with studies that used the negative expiratory pressure 270 technique to assess upper airway collapsibility, as a mean of identifying patients at risk for 271 OSA. ${ }^{24}$ This technique consists in applying a slightly negative pressure of -5 to $-10 \mathrm{~cm}_{2} \mathrm{O}$ at the 272 mouth at the early expiration phase of quiet tidal breathing and comparing the ensuing FV-C with 273 that observed during a control expiration. Negative expiratory pressure application elicits a flow 274 spike, which can exceed $2.5 \mathrm{~L} / \mathrm{s}$ during passive exhalation, despite the only slightly negative 275 pressure. This spike is ascribed mainly to dynamic airway compression of the compliant oral and 276 neck structures. ${ }^{24}$ After the spike, flow decreases to a low value, due to an increase in resistance 277 of the oropharyngeal structures, which reflects upper airway collapsibility (extrathoracic 278 expiratory flow limitation). ${ }^{24}$ It has been demonstrated that this transient spike in expiratory flow 279 correlates with the severity of OSA. ${ }^{24}$ Compared to those used for the negative expiratory 
280 pressure technique, our conditions of negative pressure application were different: the inspiratory

281 and expiratory efforts during coughing were maximal or submaximal, and the expiratory

282 pressures were considerably lower. Nevertheless, our hypothesis that a high PCF value recorded

283 at the airway opening does not necessarily indicate cough efficiency throughout the bronchial tree

284 is supported by a recent bench study, in which an MI-E device was attached to a lung simulator

285 with and without a collapsible tube. ${ }^{27} \mathrm{PCF}$ values were higher with than without the collapsible

286 tube. The collapsible tube clearly tends to decrease PCF upstream, while increasing PCF

287 downstream due to the additional flow produced by tube wall displacement.

288 In profile $\mathrm{C}$ seen in 5 of the 27 patients and characterized by early UAC, ECV remained

289 below $200 \mathrm{~mL}$. A likely explanation is that a major portion of the ECV in this situation was the

290 volume ejected from the collapsing upper airway previously expanded by the insufflation

291 preceding the exsufflation. Previous studies suggest that upper airway volume may be far less

292 than $200 \mathrm{~mL}{ }^{28,29}$ Insufflation might result in a larger volume, due to upper airway expansion.

293 However, adduction of laryngeal structures during insufflation has been reported. ${ }^{18}$ In addition,

294 upper airway narrowing during exsufflation never results in complete obstruction. ${ }^{19}$

We chose ECV, i.e., the volume exhaled above a flow rate of $3 \mathrm{~L} / \mathrm{s}$, to assess cough

efficiency. The volume exhaled at flow rates above the threshold usually considered to be

297 efficient during coughing, ${ }^{6}$ i.e., $3 \mathrm{~L} / \mathrm{s}$, is relevant. In addition, $\mathrm{ECV}$ is easy to determine from

298 flow-volume curves in everyday practice.

In our study, the occurrence of suspected UAC during the application of negative

300 exsufflation pressures was not related to the severity of the respiratory muscle dysfunction.

301 However, all 4 patients with spinal muscular atrophy had suspected UAC. This result is not

302 surprising, given that patients with spinal muscular atrophy often exhibit upper airway

303 dysfunction, which may increase the risk of upper airway collapse during MI-E. Thus, studies 
304 have established that the decrease in hypopharyngeal cross-section surface area seen during

305 exsufflation in patients with amyotrophic lateral sclerosis was more marked in the subgroup with

306 bulbar symptoms. ${ }^{18}$ Upper airway dysfunction may also be prevalent in spinal muscular atrophy,

307 as chewing and swallowing difficulties have been documented in $28 \%$ and $25 \%$ of patients with

308 type II disease, respectively. ${ }^{30}$ Unfortunately, because our study was observational we were

309 unable to modify our standard practice of confining the evaluation to spirometry, which is

310 currently viewed as the reference standard for PCF measurement. Therefore, upper airway

311 function was not routinely investigated. Nevertheless, all 5 patients with profile $C$, characterized

312 by upper airway collapse starting at the first negative pressure level $\left(-20 \mathrm{cmH}_{2} \mathrm{O}\right)$, including 3 of

313 the 4 patients with spinal muscular atrophy, reported swallowing difficulties consistent with

314 severe upper airway dysfunction. These results strongly support a need for accurately

315 determining the optimal MI-E negative pressure in patients with NMD and inefficient cough,

316 particularly when bulbar symptoms are present. Flow-volume curve analysis can be an efficient

317 tool for achieving this goal.

319 Study Limitations

320 An important limitation of this study is that performance was evaluated only during

321 spirometry. To date, it is unclear whether PCF, ECV, or the flow-volume curve profile is most

322 important for assessing cough efficiency. Nevertheless, a negative exsufflation pressure that

323 decreases ECV may limit cough efficiency. It may be appropriate to discuss the trade-off between

324 improving PCF and keeping the flow-volume curve unaltered. In addition, when the flow-

325 volume curve profile suggests UAC occurring at the beginning of negative exsufflation pressure

326 titration (profile C), further decreasing the exsufflation pressure is unlikely to be beneficial. Thus,

327 in our patients with profile $\mathrm{C}$, decreasing the exsufflation pressure had little effect on ECV, which 
328 remained below $200 \mathrm{~mL}$. Alternative or additional techniques, such as manual assisted coughing,

329 may be beneficial ${ }^{31}$ by increasing airway pressure and possibly preventing UAC during

330 exsufflation, but were not tested in our study. These points should be addressed by future

331 research. In addition, flow-volume curve analysis should be included in guidelines about optimal

332 MI-E titration. We did not test negative exsufflation pressures above $-20 \mathrm{cmH}_{2} \mathrm{O}$, which is the

333 highest initial pressure setting suggested in the literature. ${ }^{16}$ Finally, we did not evaluate patient

334 comfort or subjective cough effectiveness. However, in a previous study using various inflation

335 techniques, we found no association of cough performance with subjective impressions. ${ }^{31}$ Finally,

336 patient position may have an important impact on respiratory performances. Postural adjustments

337 were made according to patients' opinion on their best respiratory comfort. We did not describe

338 the position on the wheelchair (degree of tilt, recline or elevating leg rests measures). They might

339 be important to control in future studies.

\section{Conclusions}

In conclusion, in some patients with NMD, decreasing the negative exsufflation pressure

343 used for MI-E was associated with a decline in the volume exhaled at a flow rate above $3 \mathrm{~L} / \mathrm{s}$

344 (ECV), suggesting UAC. This decline in ECV was accompanied with an increase in PCF, which

345 thus failed to detect UAC. Our findings suggest that analysis of the maximal expiratory flow-

346 volume curve, with ECV measurement, may improve the identification of the negative

347 exsufflation pressure associated with maximal cough efficiency.

350 Funding: This research did not receive any specific grant from funding agencies in the public,

351 commercial, or not-for-profit sectors. 


\section{REFERENCES}

\section{3}

354

355

356

357

358

359

360

361

362

363

364

365

366

367

368

369

370

371

372

373

374

375

376

377

378

379

380

381

382

383

384

385

386

387

388

389

390

391

392

393

394

395

1. Ambrosino N, Carpene N, Gherardi M. Chronic respiratory care for neuromuscular diseases in adults. Eur Respir J 2009;34(2):444-51.

2. Benditt JO, Boitano LJ. Pulmonary issues in patients with chronic neuromuscular disease. Am J Respir Crit Care Med 2013;187(10):1046-55.

3. Bach JR. Mechanical insufflation-exsufflation. Comparison of peak expiratory flows with manually assisted and unassisted coughing techniques. Chest 1993;104(5):1553-62.

4. Hull J, Aniapravan R, Chan E, Chatwin M, Forton J, Gallagher J et al. British Thoracic Society guideline for respiratory management of children with neuromuscular weakness. Thorax 2012;67 Suppl 1:i1-40.

5. Bott J, Blumenthal S, Buxton M, Ellum S, Falconer C, Garrod R et al. Guidelines for the physiotherapy management of the adult, medical, spontaneously breathing patient. Thorax 2009;64 Suppl 1:i1-51.

6. Chatwin M, Toussaint M, Goncalves MR, Sheers N, Mellies U, Gonzales-Bermejo J et al. Airway clearance techniques in neuromuscular disorders: A state of the art review. Respiratory medicine 2018;136:98-110.

7. Bach JR, Saporito LR. Criteria for extubation and tracheostomy tube removal for patients with ventilatory failure. A different approach to weaning. Chest 1996;110(6):1566-71.

8. Bach JR, Ishikawa Y, Kim H. Prevention of pulmonary morbidity for patients with Duchenne muscular dystrophy. Chest 1997;112(4):1024-8.

9. Dohna-Schwake C, Ragette R, Teschler H, Voit T, Mellies U. Predictors of severe chest infections in pediatric neuromuscular disorders. Neuromuscular disorders : NMD 2006;16(5):325-8.

10. Boitano LJ. Management of airway clearance in neuromuscular disease. Respiratory care 2006;51(8):913-22; discussion 22-4.

11. Leger P, Paulus J. [Recommendations of HAS: Practical issues in home non-invasive ventilation in patients with neuromuscular disease]. Revue des maladies respiratoires 2006;23(4 Suppl):13S141-3.

12. Rokadia HK, Adams JR, McCarthy K, Aboussouan LS, Mireles-Cabodevila E. Cough Augmentation in a Patient with Neuromuscular Disease. Annals of the American Thoracic Society 2015;12(12):1888-91.

13. Sancho J, Servera E, Banuls P, Marin J. Effectiveness of assisted and unassisted cough capacity in amyotrophic lateral sclerosis patients. Amyotrophic lateral sclerosis \& frontotemporal degeneration 2017;18(7-8):498-504.

14. Toussaint M, Boitano LJ, Gathot V, Steens M, Soudon P. Limits of effective coughaugmentation techniques in patients with neuromuscular disease. Respiratory care 2009;54(3):359-66.

15. Suarez AA, Pessolano FA, Monteiro SG, Ferreyra G, Capria ME, Mesa L et al. Peak flow and peak cough flow in the evaluation of expiratory muscle weakness and bulbar impairment in patients with neuromuscular disease. Am J Phys Med Rehabil 2002;81(7):506-11.

16. Morrow B, Zampoli M, van Aswegen H, Argent A. Mechanical insufflation-exsufflation for people with neuromuscular disorders. The Cochrane database of systematic reviews 2013;12:CD010044. 
17. Mellies U, Goebel C. Optimum insufflation capacity and peak cough flow in neuromuscular disorders. Annals of the American Thoracic Society 2014;11(10):1560-8. 18. Andersen T, Sandnes A, Brekka AK, Hilland M, Clemm H, Fondenes O et al. Laryngeal response patterns influence the efficacy of mechanical assisted cough in amyotrophic lateral sclerosis. Thorax 2017;72(3):221-9.

19. Sancho J, Servera E, Diaz J, Marin J. Efficacy of mechanical insufflation-exsufflation in medically stable patients with amyotrophic lateral sclerosis. Chest 2004;125(4):1400-5. 20. Standardized lung function testing. Official statement of the European Respiratory Society. Eur Respir J 1993;16 Suppl:1-100.

21. Hart N, Polkey MI, Sharshar T, Falaize L, Fauroux B, Raphael JC et al. Limitations of sniff nasal pressure in patients with severe neuromuscular weakness. Journal of neurology, neurosurgery, and psychiatry 2003;74(12):1685-7.

22. Trebbia G, Lacombe M, Fermanian C, Falaize L, Lejaille M, Louis A et al. Cough determinants in patients with neuromuscular disease. Respiratory physiology \& neurobiology 2005;146(2-3):291-300.

23. Miller MR, Hankinson J, Brusasco V, Burgos F, Casaburi R, Coates A et al. Standardisation of spirometry. Eur Respir J 2005;26(2):319-38.

24. Insalaco G, Romano S, Marrone O, Salvaggio A, Bonsignore G. A new method of negative expiratory pressure test analysis detecting upper airway flow limitation to reveal obstructive sleep apnea. Chest 2005;128(4):2159-65.

25. R Development Core Team. R: A Language and Environment for Statistical Computing n.d. [cited 2019 June 3rd]. Available from: URL: http://www.R-project.org.

26. Mead J, Turner JM, Macklem PT, Little JB. Significance of the relationship between lung recoil and maximum expiratory flow. Journal of applied physiology 1967;22(1):95-108.

27. Lachal R, Louis B, Subtil F, Guerin C. Bench Assessment of the Effect of a Collapsible Tube on the Efficiency of a Mechanical Insufflation-Exsufflation Device. Respir Care 2019. 28. Chousangsuntorn K, Bhongmakapat T, Apirakkittikul N, Sungkarat W, Supakul N, Laothamatas J. Upper Airway Areas, Volumes, and Linear Measurements Determined on Computed Tomography During Different Phases of Respiration Predict the Presence of Severe Obstructive Sleep Apnea. Journal of oral and maxillofacial surgery : official journal of the American Association of Oral and Maxillofacial Surgeons 2018;76(7):1524-31. 29. Boutet C, Abdirahman Mohamed Moussa S, Celle S, Laurent B, Barthelemy JC, Barral FG et al. Supra-Epiglottic Upper Airway Volume in Elderly Patients with Obstructive Sleep Apnea Hypopnea Syndrome. PloS one 2016;11(6):e0157720.

30. Messina S, Pane M, De Rose P, Vasta I, Sorleti D, Aloysius A et al. Feeding problems and malnutrition in spinal muscular atrophy type II. Neuromuscular disorders : NMD 2008;18(5):389-93.

31. Lacombe M, Del Amo Castrillo L, Bore A, Chapeau D, Horvat E, Vaugier I et al. Comparison of three cough-augmentation techniques in neuromuscular patients: mechanical insufflation combined with manually assisted cough, insufflation-exsufflation alone and insufflation-exsufflation combined with manually assisted cough. Respiration; international review of thoracic diseases 2014;88(3):215-22. 


\section{SUPPLIERS}

a. Spirometer: Medisoft, Sorinnes, Belgium

b. Facemask: Ambu, Bordeaux, France

c. Mechanical insufflation-exsufflation device: JH Emerson Co., Cambridge, MA, USA

\section{FIGURE LEGENDS}

\section{Figure 1}

Example of two flow-volume curves obtained during coughing and two different negative pressure applications. The solid line was obtained at a lower pressure than the dotted line and indicated a flow rate decrease for part of the exhaled volume compared to the dotted line, suggesting transient upper airway collapse (UAC). Cough performance was assessed based on the effective cough volume (ECV), defined as the volume exhaled at a flow rate above $3 \mathrm{~L} / \mathrm{s}(180$ L/min). See text for details.

\section{Figure 2}

Examples of each of the three flow-volume curve profiles (A, B, and C) during titration of the negative exsufflation pressure applied during mechanical in-exsufflation.

A: No upper airway collapse (UAC) : Peak cough flow (PCF) and the effective cough volume (ECV) increase.

B: UAC occurs at a specific exsufflation pressure (in this example at $-50 \mathrm{cmH}_{2} \mathrm{O}$, confirmed at $\left.-60 \mathrm{cmH}_{2} \mathrm{O}\right)$ : PCF increases, ECV decreases. 
466 stable when expiratory pressure decreases.

467 See the results section for more details.

468

$469 \quad$ Figure 3

470 Peak cough flow changes according to the level of negative expiratory pressure applied

$473 \quad$ Figure 4

474 Individual relationships between peak cough flow (PCF) and effective cough volume (ECV)

475 during negative exsufflation pressure titration in patients with profile A (left panel, $n=12$ ) and in

476 those with profile $\mathrm{B}$ or $\mathrm{C}$ (right panel, $\mathrm{n}=15$ ). The three profiles are described in Figure 2 and

477 Table 2.

478

479 
Figure 1:

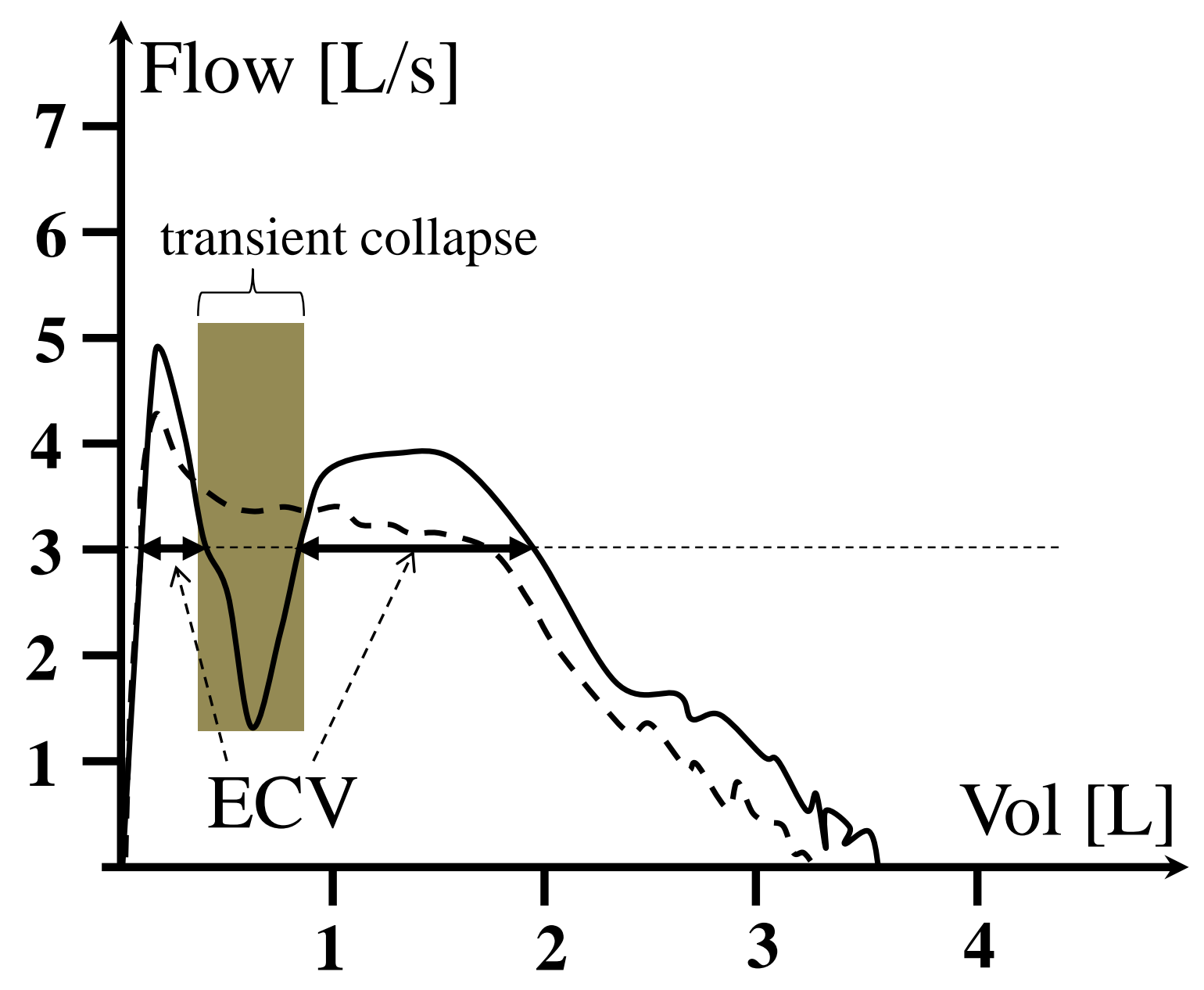




\section{Figure 2:}

$-20 \mathrm{cmH}_{2} \mathrm{O} \quad-30 \mathrm{cmH}_{2} \mathrm{O} \quad-40 \mathrm{cmH}_{2} \mathrm{O} \quad-50 \mathrm{cmH}_{2} \mathrm{O} \quad-60 \mathrm{cmH}_{2} \mathrm{O}$
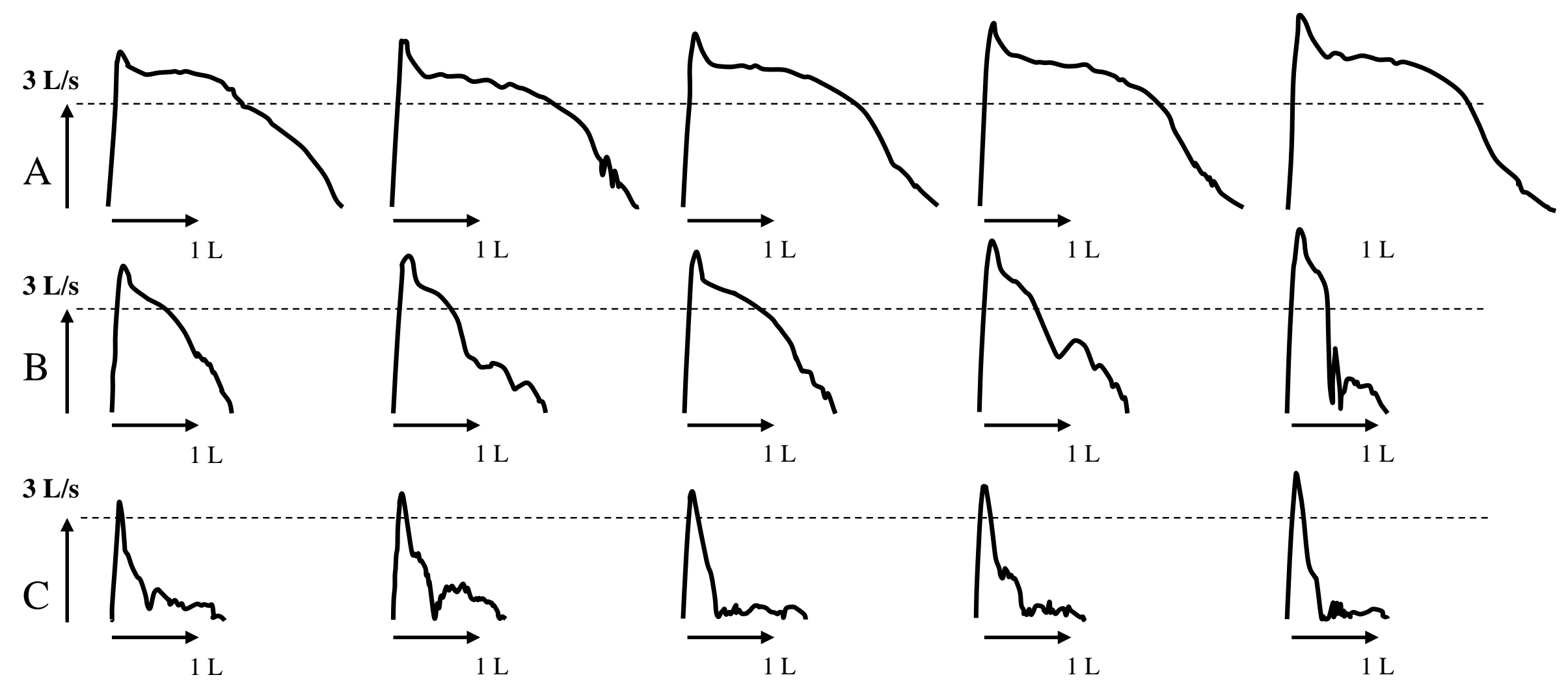


\section{Figure 3 :}

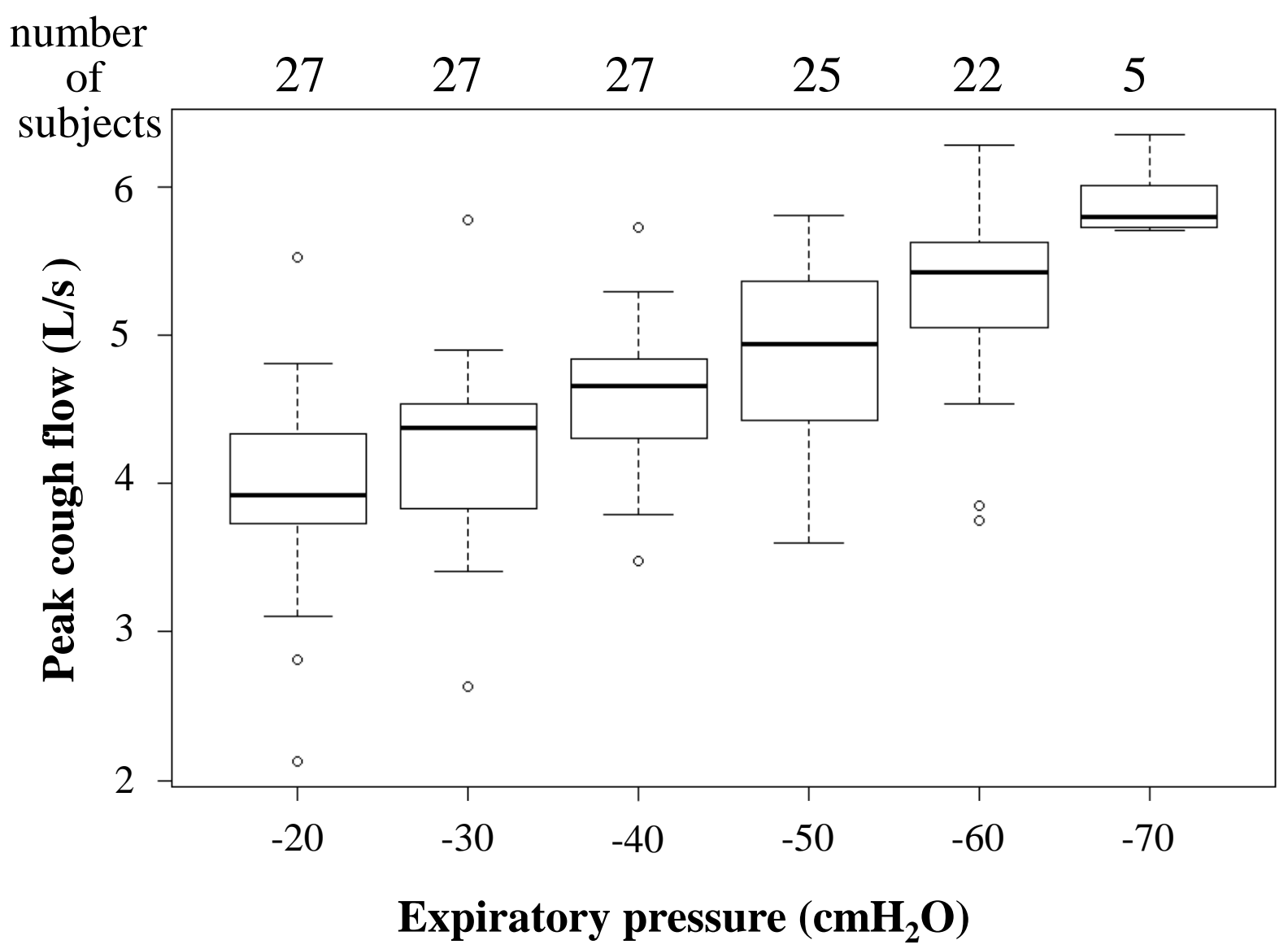




\section{Figure 4 :}
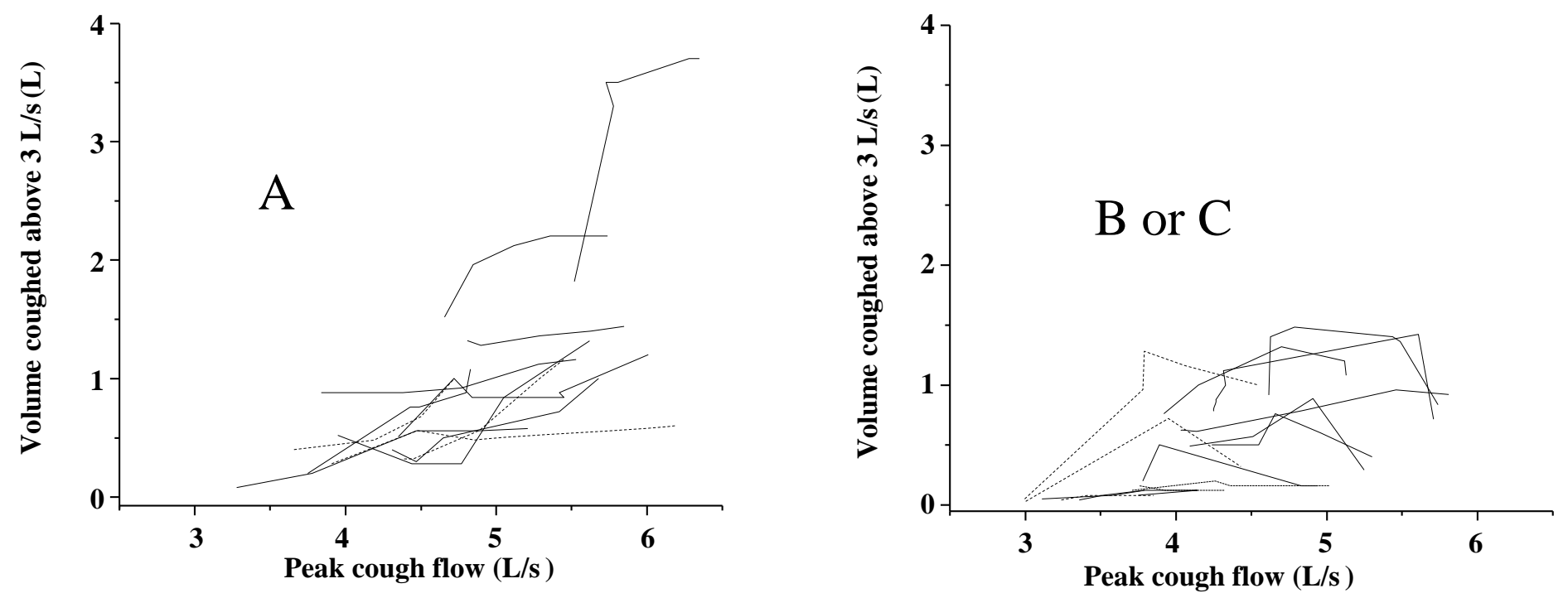
Table 1: Baseline characteristics of the 27 patients with neuromuscular disease

\begin{tabular}{lc}
\hline Characteristics & $\begin{array}{c}\text { Population } \\
\mathbf{n = 2 7}\end{array}$ \\
\hline Diagnosis, n (\%) & $14(51)$ \\
Duchenne Muscular Dystrophy & $4(15)$ \\
Limb Girdle Muscular Dystrophy 2C & $4(15)$ \\
Spinal Muscular Atrophy & $2(7)$ \\
Limb Girdle Muscular Dystrophy 2D & $1(4 \%)$ \\
Congenital Myasthenia Gravis & $1(4)$ \\
Charcot Marie-Tooth & $1(4)$ \\
Mitochondrial Myopathy & $30.6( \pm 9.2)$ \\
Age, years & $16(59)$ \\
Male gender, n (\%) & $10.4( \pm 5.8)$ \\
MV duration (hour/day) & $20.2( \pm 11.8)$ \\
Upright VC, \% & $20.3( \pm 13.9)$ \\
MIP, cmH $\mathrm{O}_{2} \mathrm{O}$ & $18.2( \pm 10.7)$ \\
MEP, cmH $\mathrm{H}_{2} \mathrm{O}$ & $161.4( \pm 52.6)$ \\
PCF, Liter/sec &
\end{tabular}

The data are mean \pm SD unless specified otherwise. VC, vital capacity as $\%$ of the predicted value according to Quanjer et al. ${ }^{20}$; PCF, peak cough flow; MEP, maximal expiratory pressure; MIP, maximal inspiratory pressure; MV, mechanical ventilation 
Table 2. Characteristics of the 27 patients with neuromuscular disease and chronic respiratory failure

\begin{tabular}{|c|c|c|c|c|c|c|c|c|c|c|}
\hline Profile & & Sex/Age & Diagnosis & $\begin{array}{c}\text { MV } \\
\text { duration }\end{array}$ & $\begin{array}{c}\text { VC } \\
\text { seated }\end{array}$ & MIP/MEP & PCF & $\begin{array}{c}\text { Highest } \\
\text { IP/EP } \\
\text { tested }\end{array}$ & $\begin{array}{c}\text { PCF/ECV } \\
\text { at the } \\
\text { highest } \\
\text { IP/EP }\end{array}$ & $\begin{array}{c}\text { Best } \\
\text { ECV and } \\
\text { its EP }\end{array}$ \\
\hline & & years & & h/day & $\%$ & $\mathrm{cmH}_{2} \mathrm{O}$ & L. $\min ^{-1}$ & $\mathrm{cmH}_{2} \mathrm{O}$ & L. $\min ^{-1} / \mathrm{L}$ & $\mathrm{L} / \mathrm{cmH}_{2} \mathrm{O}$ \\
\hline A & 2 & $\mathrm{M} / 22$ & DMD & 8 & 23 & $32 / 23$ & 184 & $24 /-70$ & $381 / 3.70$ & $3.70 /-70$ \\
\hline A & 3 & $\mathrm{M} / 32$ & LGMD2C & 8 & 16 & $16 / 16$ & 135 & $34 /-60$ & $344 / 2.20$ & $2.20 /-60$ \\
\hline A & 4 & $\mathrm{~F} / 43$ & CMT & 15 & 23 & $11 / 19$ & 178 & $34 /-70$ & $312 / 0.58$ & $0.58 /-70$ \\
\hline A & 6 & $\mathrm{M} / 20$ & DMD & 24 & 11 & $21 / 15$ & 159 & $38 /-70$ & $361 / 1.20$ & $1.20 /-70$ \\
\hline A & 9 & $\mathrm{M} / 40$ & LGMD2C & 10 & 12 & $13 / 13$ & 107 & $28 /-60$ & $332 / 1.16$ & $1.16 /-60$ \\
\hline A & 12 & $\mathrm{M} / 25$ & DMD & 10 & 32 & $25 / 20$ & 236 & $24 /-70$ & $348 / 0.96$ & $0.96 /-70$ \\
\hline A & 15 & $\mathrm{M} / 21$ & DMD & 8 & 14 & $19 / 21$ & 250 & $28 /-60$ & $337 / 0.60$ & $0.60 /-60$ \\
\hline A & 22 & $F / 26$ & LGMD2C & 0 & 36 & $37 / 30$ & 239 & $40 /-60$ & $327 / 1.16$ & $1.16 /-60$ \\
\hline A & 23 & $\mathrm{M} / 33$ & DMD & 23 & 11 & $8 / 9$ & 119 & $34 /-60$ & $351 / 1.44$ & $1.44 /-60$ \\
\hline A & 25 & $\mathrm{M} / 22$ & DMD & 12 & 24 & $9 / 9$ & 145 & $34 /-60$ & 290/1.08 & $1.08 /-60$ \\
\hline A & 26 & $\mathrm{M} / 26$ & DMD & 8 & 17 & $15 / 25$ & 195 & $28 /-60$ & $337 / 1.32$ & $1.32 /-60$ \\
\hline A & 27 & $\mathrm{~F} / 56$ & $\mathrm{MM}$ & 12 & 52 & $28 / 55$ & 227 & $40 /-60$ & $284 / 1.00$ & $1.00 /-60$ \\
\hline $\mathrm{B}$ & 5 & $\mathrm{M} / 21$ & DMD & 16 & 9 & $11 / 10$ & 160 & $34 /-60$ & $344 / 0.92$ & $1.44 /-50$ \\
\hline $\mathrm{B}$ & 7 & $\mathrm{M} / 23$ & DMD. & 12 & 17 & $17 / 19$ & 203 & $30 /-70$ & $342 / 0.80$ & $1.50 /-60$ \\
\hline $\mathrm{B}$ & 8 & $\mathrm{M} / 22$ & DMD & 15 & 10 & $13 / 14$ & 154 & $36 /-50$ & $296 / 0.16$ & $0.50 /-40$ \\
\hline $\mathrm{B}$ & 10 & $\mathrm{M} / 27$ & DMD. & 18 & 8 & $9 / 5$ & 128 & $30 /-60$ & $349 / 0.92$ & $0.96 /-50$ \\
\hline $\mathrm{B}$ & 11 & $\mathrm{~F} / 24$ & DMD & 8 & 24 & $13 / 8$ & 215 & $34 /-60$ & $305 / 1.32$ & $1.60 /-50$ \\
\hline $\mathrm{B}$ & 13 & $\mathrm{~F} / 38$ & LGMD2D & 8 & 14 & $11 / 11$ & 141 & $34 /-60$ & $318 / 0.40$ & $0.60 /-50$ \\
\hline $\mathrm{B}$ & 16 & $\mathrm{M} / 23$ & DMD & 9 & 13 & $10 / 11$ & 187 & $30 /-60$ & $316 / 0.40$ & $0.60 /-50$ \\
\hline $\mathrm{B}$ & 18 & $\mathrm{~F} / 30$ & SA & 0 & 50 & $67 / 37$ & 220 & $30 /-60$ & $272 / 1.00$ & $1.16 /-50$ \\
\hline $\mathrm{B}$ & 20 & $\mathrm{~F} / 42$ & LGMD2C & 10 & 12 & $9 / 9$ & 130 & $24 /-60$ & $308 / 1.08$ & $1.32 /-50$ \\
\hline $\mathrm{B}$ & 24 & $\mathrm{~F} / 44$ & LGMD2D & 10 & 15 & $7 / 10$ & 130 & $30 /-50$ & $266 / 0.32$ & $0.72 /-40$ \\
\hline $\mathrm{C}$ & 1 & $F / 37$ & SA & 0 & 30 & $40 / 27$ & 122 & $34 /-40$ & $227 / 0.12$ & $0.12 /-40$ \\
\hline $\mathrm{C}$ & 14 & $\mathrm{~F} / 25$ & DMD & 9 & 14 & $18 / 29$ & 142 & $24 /-40$ & $259 / 0.12$ & $0.12 /-40$ \\
\hline $\mathrm{C}$ & 17 & M/39 & SA & 8 & 12 & $21 / 15$ & 69 & $40 /-60$ & $231 / 0.08$ & $0.08 /-60$ \\
\hline $\mathrm{C}$ & 19 & $F / 33$ & SA & 12 & 12 & $22 / 14$ & 104 & $34 /-50$ & $248 / 0.12$ & $0.12 /-50$ \\
\hline $\mathrm{C}$ & 21 & $\mathrm{~F} / 32$ & CMS & 8 & 33 & $46 / 16$ & 179 & $28 /-60$ & $301 / 0.16$ & $0.16 /-60$ \\
\hline
\end{tabular}

Abbreviations: MV, mechanical ventilation; F, female; M, male; VC, vital capacity; MIP, maximal inspiratory pressure; MEP, maximal expiratory pressure; PCF, peak cough flow; IP, insufflation pressure; EP, exsufflation pressure; ECV, effective cough volume; DMD, Duchenne muscular dystrophy; SA, spinal muscular atrophy; CMT, Charcot-Marie-Tooth disease; LGMD2C, limb-girdle muscular dystrophy type 2C; LGMD2D, limb-girdle muscular dystrophy type 2D; CMG, congenital myasthenic syndrome; MM, mitochondrial myopathy; A, B, and C profiles, flow-volume profiles depicted in Figure 2 